PHYSICAL REVIEW X 6, 019901 (2016)

\title{
Publisher's Note: Photon Temporal Modes: A Complete Framework for Quantum Information Science [Phys. Rev. X 5, 041017 (2015)]
}

B. Brecht, Dileep V. Reddy, C. Silberhorn, and M. G. Raymer

(Received 20 January 2016; published 28 January 2016)

DOI: 10.1103/PhysRevX.6.019901

Subject Areas: Quantum Information

This paper was published online on 30 October 2015 with an incorrect author list in Ref. [19]. Reference [19] should read as "J. Roslund, R. M. de Araújo, S. Jiang, C. Fabre, and N. Treps, Wavelength-Multiplexed Quantum Networks with Ultrafast Frequency Combs, Nat. Photonics 8, 109 (2013)." The reference has been corrected as of 21 January 2016.

Published by the American Physical Society under the terms of the Creative Commons Attribution 3.0 License. Further distribution of this work must maintain attribution to the author(s) and the published articles title, journal citation, and DOI. 